\title{
A PREDICTIVE MODEL FOR BOILING HEAT TRANSFER COEFFICIENT OF DIELECTRIC FLUIDS ON METAL FOAMS
}

\author{
Leonardo L. Manetti ${ }^{1}$, Ana Sofia Oliveira Henriques Moita ${ }^{3}$ and Elaine Maria Cardoso ${ }^{1,2^{*}}$ \\ ${ }^{1}$ UNESP - São Paulo State University, School of Engineering, Post-Graduation Program in Mechanical \\ Engineering, Av. Brasil, 56, 15385-000, Ilha Solteira, SP, Brazil \\ ${ }^{2}$ UNESP - São Paulo State University, Campus of São João da Boa Vista \\ ${ }^{3} \mathrm{IN}+$, Dep. Mechanical Engineering, Instituto Superior Técnico, Universidade de Lisboa, Lisbon, Portugal
}

\begin{abstract}
Pool boiling is a suitable technique for direct immersion cooling in electronic devices coupled with dielectric fluids. However, these fluids have relatively poor thermophysical properties in contrast to water, and extremely small contact angle that causes temperature overshooting at the boiling incipience. So, the use of surface enhancement techniques such as porous surfaces has been widely reported to enhance heat transfer performance and meet the cooling requirements. The porous thickness and pore size are the most important parameters of a porous surface, and their optimal values mainly depend on the fluid properties. This work aims to investigate the performance of metal foams of nickel and copper, with different pore diameter and thicknesses on pool boiling, using HFE-7100 as working fluid. A predictive model was proposed for the heat transfer coefficient (HTC) based on the Buckingham $\pi$ theorem and experimental database. Additional data were taken from the literature for comparative purposes. The dimensionless numbers showed a greater contribution of the transient heat conduction and single-phase convection than the latent heat. In addition, as the pore diameter decreases the HTC increases. The thickness presents a variable exponent, which is a function of the heat flux, due to the balance of heat transfer area and vapor bubble resistance. The developed model accurately predicts $93 \%$ of the experimental data within an error band of $\pm 30 \%$ and absolute mean deviation of $13 \%$; moreover, the developed model predicts $68 \%$ (within the $\pm 30 \%$ error band) of data from the literature for different working fluids and foams parameters.
\end{abstract}

KEYWORDS: pool boiling, metal foams, heat transfer coefficient, predictive model, HFE-7100.

\section{INTRODUCTION}

Two-phase cooling systems have been widely studied for thermal management technology. Pool boiling is a low-cost technique due to buoyancy of the bubbles in the absence of a pump. It can be used with direct immersion cooling for an increased power density and energy efficiency in cooling high power electronics [3-5]. Although water possesses a higher boiling heat transfer coefficient, it is not compatible with electronic devices for direct immersion cooling due to the problem of electrical short-circuit; on the other hand, dielectric fluids such as fluorochemical liquids are not electrically conductive and it has been proved to be highly suitable as a liquid medium for cooling [4]. However, these fluids have relatively poor thermophysical properties and extremely small contact angle that causes large superheat to initiate the boiling process - commonly referred to as 'incipience excursion' [5]. Therefore, the use of surface enhancement techniques is needed to meet the cooling requirements of modern electronic devices. According to Hendricks et al. [6], the heating surface can be modified by using three factors: (i) existence of random micro- or nano-size crevices and surface irregularities for bubble nucleation; (ii) porous surface structure that allows fluid inflow to keep nucleation sites active; and, (iii) surface protrusions that enlarge the boiling 
surface area. Porous surface structures have been widely reported to enhance heat transfer performance due to their interconnected porous, which increase the wetted area and the nucleation site density [7]. The porous thickness and pore size are the most important parameters of a porous surface, and their optimal values mainly depend on the fluid properties [8].

For industrial applications, a predictive model is required mainly for the heat transfer coefficient (HTC). According to $\mathrm{Wu}$ et al. [9], mechanistic models and empirical correlations have achieved some success in predicting boiling HTCs, mainly for smooth surfaces, although some of them may predict experimental data well while failing for other data sets. The former is based on the heat flux partitioning model (RPI Model), which counts various boiling heat transfer mechanisms calculated separately [10]. Generally, nucleate boiling is attributed to three heat transfer mechanisms: (1) natural convection in the region of the surface not influenced by the bubbles; (2) evaporation occurring during the bubble-growing period (term related to the latent heat of evaporation); and, (3) so-called quenching due to the inflow of cold fluid on the heating surface and subsequent thermal boundary layer re-formation after bubble departure [11]. However, the mechanistic models require information of many parameters, like bubble departure diameters and its frequencies, and active nucleation site densities. These parameters are difficult to obtain, especially the active nucleation site densities, which restricts the general validation of mechanistic models. Besides, the mechanistic models normally eliminate bubble interactions, and thus, they are not valid at high heat fluxes [12]. As a workaround, several authors proposed modeling nucleate boiling via dimensional analysis, avoiding the use of quantities that must be obtained experimentally [11].

The empirical correlations require critical analysis to find the main phenomena, properties, and dimensionless number to describe the pool boiling data set. The well-known Rohsenow's correlation [13] was developed based on a physical analogy between single-phase convection and nucleate boiling where Reynolds, Prandtl, and Stanton number are correlated [14]. Stephan and Abdelsalam [15] used regression analysis to derive the Nusselt number from other dimensionless variables. According to Stephan [16], the regression analysis showed that certain non-dimensional quantities prove to be important for some substances but unimportant for others. A disadvantage of these correlations is the fact that the composition of the heating surface has not been taken into consideration. Some of them address the effect of surface topography by considering the surface roughness. However, this parameter is not representative of the geometric features of the surface pattern and so it is weakly correlated with the quantities describing nucleation and bubble dynamics [11].

Teodori et al. [11] proposed a new correlation based on an empirical method to predict the pool-boiling heat transfer coefficients on regular micro-patterned heating surfaces. Two correlations were obtained by dimensional analysis, which were slightly different in terms of the phenomenological description of the boiling process. Both of them were able to predict the heat transfer coefficient within an error of $\pm 30 \%$. In addition, these correlations could predict fluids behavior with significantly different thermophysical properties. However, according to Lin and Kedzierski [8], the boiling models for the structured surface are not directly applicable to the porous surface due to the randomness of the porous surface geometry due to irregular geometry. It is more difficult to develop a mechanistically based model for the boiling heat transfer on a porous surface. Consequently, few studies predicting the heat transfer on porous surfaces were found in the open literature.

Nishikawa and Ito [17] developed a correlation based on their pool boiling data of R-11, R-113, and benzene at saturation temperature and atmospheric pressure on the porous surfaces coated by copper or bronze particles, whose diameter ranged from 100 to $1000 \mu \mathrm{m}$. The correlation incorporates the effects of porosity ranged from 0.38 to 0.71 - and thickness of the coating layer - ranged from 0.5 to $5 \mathrm{~mm}$, particle diameter, and fluid properties. Recently, Xu et al. [18] used Rohsenow correlation to determine the correlation for a highly porous surface - metal foams - by adding a modification factor and exponent. The effects of pore density, porosity, and thickness were included in the modified factor and exponent. For water pool boiling heat transfer, approximately $80 \%$ of the predicted data were within an error band of $\pm 30 \%$. 
Based on the literature review, the immersion cooling with porous heating surfaces has potential for industrial applications. Prior to their implementation in industrial applications, it is vital to determine their pool boiling heat transfer performance. Some researchers focus on correlation with refrigerants fluids with sintered porous layer or water on metal foams, but until now a correlation of metal foams on dielectric fluid was not found.

This work aims to develop an empirical correlation for metal foams surfaces in pool boiling with dielectric fluid, taking into account the porous heating surface characteristics (porosity, pore diameter, and thickness), the working fluid properties, and the interaction between them. The correlation is proposed based on our HTC experimental database. The developed model accurately predicts the experimental database and data from the literature for different working fluids and foams parameters.

\section{EXPERIMENTAL SETUP AND FOAM SAMPLES}

The porous surfaces used in the present study are open-cell metal foam fabricated by using the metal deposition as detailed by Ashby et al. [14] and Bahart [15]. They were purchased from Nanoshel® in $500 \times$ $500 \mathrm{~mm}^{2}$ panels with $3 \mathrm{~mm}$ thick. In order to use the foam in pool boiling tests, they were cut in a square section of $16 \times 16 \mathrm{~mm}^{2}$ by using a wire electrical discharge machining (wire-EDM). Furthermore, other foam thicknesses were used in this work. For the thickness level variation, it was used the electric discharge machining process (EDM). Table 1 shows the characteristics of each foam, such as porosity $(\varepsilon)$, mean pore diameter $\left(d_{p}\right)$, mean fiber diameter $\left(d_{f}\right)$, area density $\left(a_{s f}\right)$, and thickness $(\delta)$. These parameters were obtained by the authors as detailed in Manetti et al. [19].

Table 1 Metals foams characteristics.

\begin{tabular}{c|c|c|c|c|c}
\hline Material & $\begin{array}{c}\varepsilon \\
(\%)\end{array}$ & $\begin{array}{c}d_{p} \\
(\mathrm{~mm})\end{array}$ & $\begin{array}{c}d_{f} \\
(\mathrm{~mm})\end{array}$ & $\begin{array}{c}a_{s f} \\
\left(\mathrm{~m}^{2} / \mathrm{m}^{3}\right)\end{array}$ & $\begin{array}{c}\delta \\
(\mathrm{mm})\end{array}$ \\
\hline $\mathrm{Cu}$ & $90 \pm 0.32$ & $0.52 \pm 0.22$ & $0.09 \pm 0.04$ & 2166 & $1-3$ \\
$\mathrm{Ni}$ & $98 \pm 0.15$ & $0.22 \pm 0.10$ & $0.04 \pm 0.02$ & 5133 & $0.5-3$ \\
\hline
\end{tabular}

The foams were welded (soldering process described by Groover [20]) on the plain surface to ensure small thermal resistance between the foam and the test section (Fig. 1). The process consisted of apply a thin tin layer $(0.1 \mathrm{~mm}$ thickness) between the plain surface and the copper foam; after that, the copper block was heated by a cartridge resistance up to the tin alloy melting point $\left(\approx 200{ }^{\circ} \mathrm{C}\right)$ and a weight was put on the foam to pressure it against the plain surface. Finally, the assembly was cleaned with alcohol and acetone.

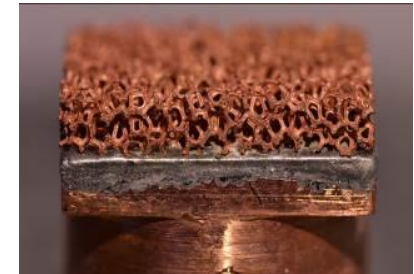

(b)

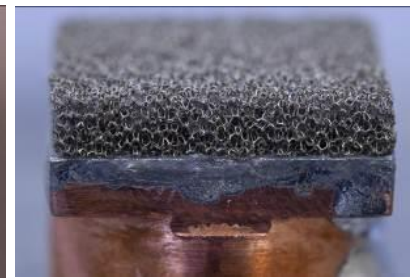

(b)

Fig. 1 Heating surfaces: (a) $\mathrm{Cu}$ foam $3 \mathrm{~mm}$; and (b) Ni foam $3 \mathrm{~mm}$.

The pool boiling tests were performed in the apparatus shown in Fig. 2, which consists of a rectangular glass vessel. Two K-type thermocouples, $T_{l i q}$, and $T_{\text {vap }}$, located in the liquid and vapor regions of the vessel, respectively, were used to monitor the test fluid temperature. An absolute pressure transducer Omega PXM309-2A measured the pressure inside the boiling chamber. The experiments were performed under conditions close to the local atmospheric pressure, $p_{a t m}=98 \mathrm{kPa}$. The test section consisted of a copper piece with a square plate on the upper surface $\left(16 \times 16 \mathrm{~mm}^{2}\right)$ of the copper cylinder. The test section was machined 
from a unique copper piece in order to avoid thermal contact resistances among its components. Three Ktype thermocouples $\left(T_{1}, T_{2}\right.$, and $\left.T_{3}\right)$ with hot junction diameters of $0.5 \mathrm{~mm}$ were embedded within the cylinder. The cylinder was fixed on a second copper block containing a heater cartridge with a maximum power of $300 \mathrm{~W}$ at $220 \mathrm{~V}$ responsible for heating the test section. This resistance was powered by a variable DC power source. The test section was thermally insulated from the environment by a radial polytetrafluoroethylene (PTFE). More details about the experimental setup and data reduction can be found in Manetti et al. [19].

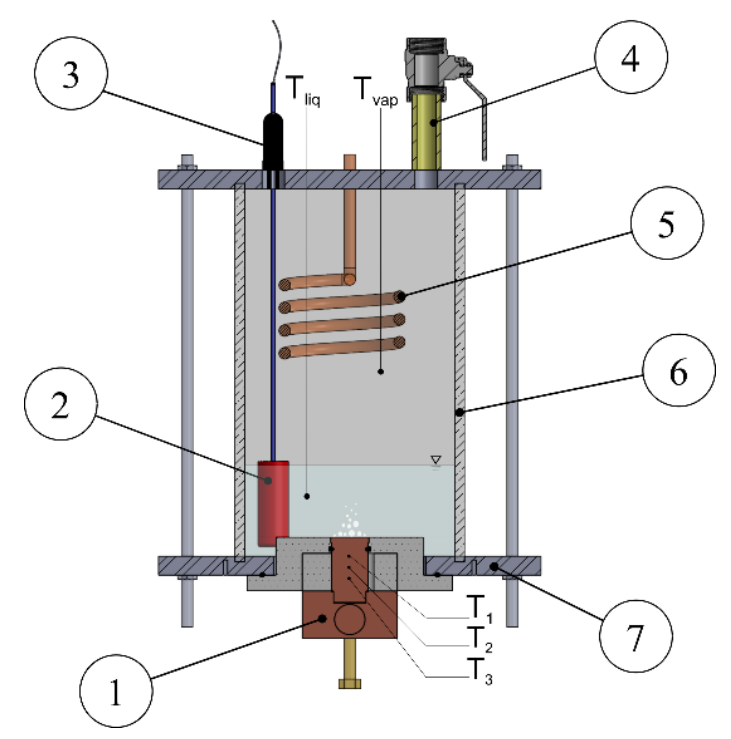

Fig. 2 Pool boiling apparatus: (1) cooper block; (2) auxiliary heater; (3) pressure transducer; (4) vacuum/feed valve; (5) cooling coil; (6) glass chamber; (7) stainless steel plate.

The boiling tests were performed by using HFE-7100 $\left(3 \mathrm{M}^{\mathrm{TM}} \mathrm{Novec}^{\mathrm{TM}}\right)$ at saturated conditions - physical properties are listed in Table 2.

Table 2 Thermophysical properties of HFE-7100 at saturated conditions [21, 22].

\begin{tabular}{l|r|r|r|r|r|r|r|r}
\hline $\begin{array}{l}\text { Saturation } \\
\text { pressure }\end{array}$ & $\begin{array}{r}\mathrm{T}_{\text {sat }} \\
\left({ }^{\circ} \mathrm{C}\right)\end{array}$ & $\begin{array}{r}\rho_{\mathrm{l}} \\
\left(\mathrm{kg} / \mathrm{m}^{3}\right)\end{array}$ & $\begin{array}{r}\rho_{\mathrm{v}} \\
\left(\mathrm{kg} / \mathrm{m}^{3}\right)\end{array}$ & $\begin{array}{r}10^{6} \times \mu_{1} \\
(\mathrm{~Pa} . \mathrm{s})\end{array}$ & $\begin{array}{r}\mathrm{c}_{\mathrm{p}, \mathrm{l}} \\
(\mathrm{J} / \mathrm{kg} \cdot \mathrm{K})\end{array}$ & $\begin{array}{r}\mathrm{h}_{\mathrm{lv}} \\
(\mathrm{kJ} / \mathrm{kg})\end{array}$ & $\begin{array}{r}\mathrm{k}_{\mathrm{l}} \\
(\mathrm{W} / \mathrm{m} . \mathrm{K})\end{array}$ & $\begin{array}{r}\sigma \\
(\mathrm{mN} / \mathrm{m})\end{array}$ \\
\hline $1 \mathrm{~atm}$ & 61.0 & 1418 & 9.7 & 426.8 & 1255.0 & 111.6 & 0.069 & 10.20 \\
$98 \mathrm{kPa}^{\mathrm{a}}$ & 60.3 & 1420 & 9.5 & 430.5 & 1253.6 & 111.9 & 0.069 & 10.26 \\
\hline
\end{tabular}

The test conditions were adjusted by monitoring the pressure and the temperature inside the boiling chamber. For each metal foam test, the experiment was carried out at least twice under similar conditions to ensure that the results were repeatable and increase the experimental database for the predictive model. The experimental uncertainty of the heat transfer coefficient is higher for low heat fluxes, decreasing as heat fluxes increase. For all surfaces tested, the experimental uncertainty for the heat flux and the heat transfer coefficient varied from $18.3 \%$ to $3.3 \%$ and from $18.4 \%$ to $3.8 \%$, respectively.

\section{RESULTS AND DISCUSSIONS}

\subsection{Metal Foams Boiling Curves}

The first run of the experimental database - boiling curves for both metal foams, $\mathrm{Cu}$ and $\mathrm{Ni}$ - are presented in Fig. 3. In addition, Fig. 4 shows the HTC curves for both surfaces. 


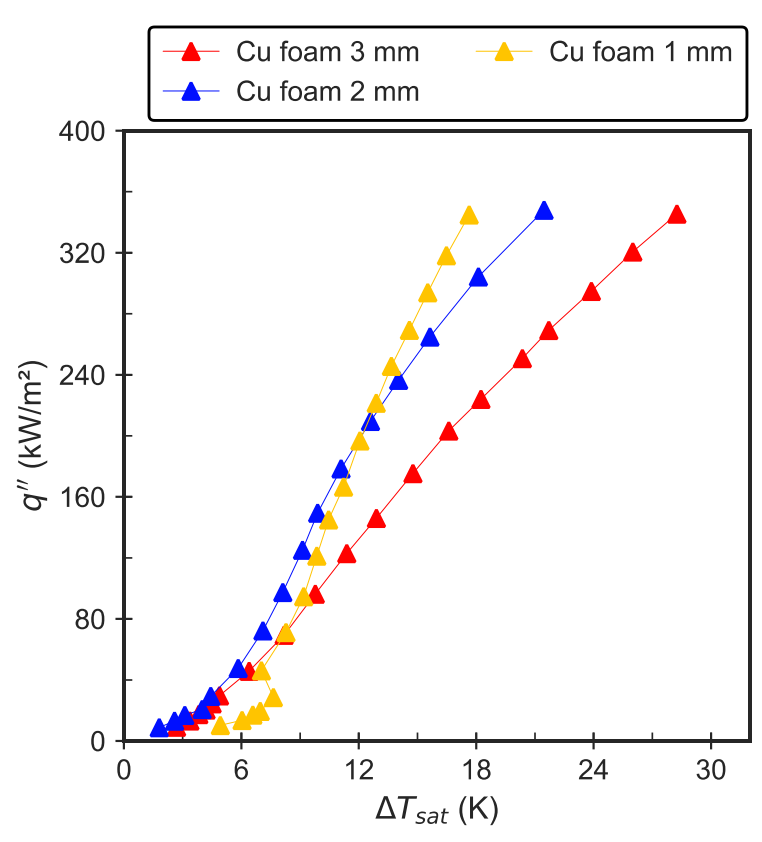

(a)

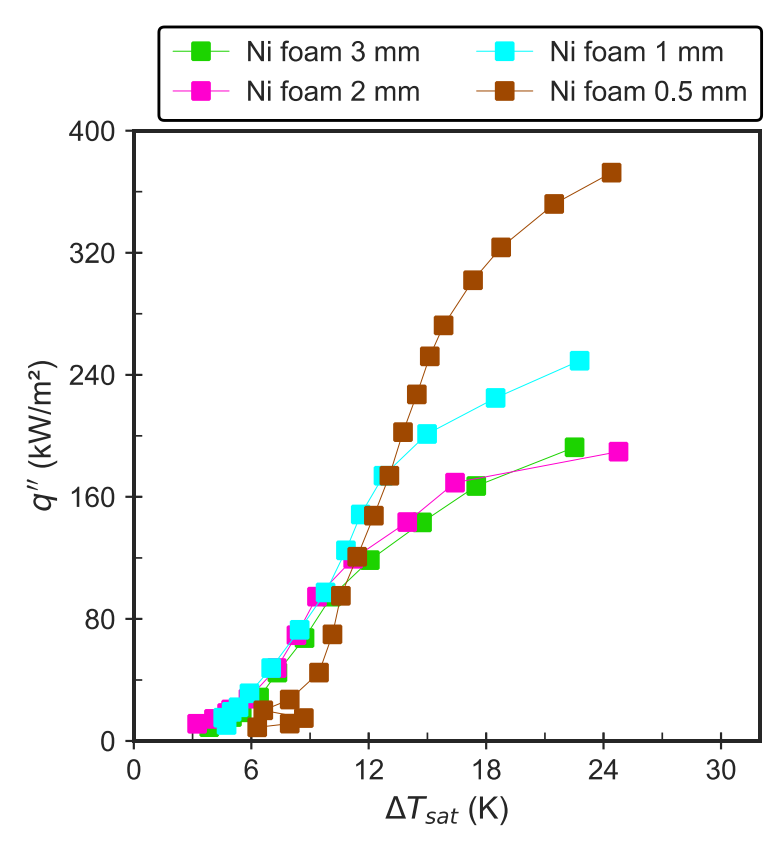

(b)

Fig. 3 Pool boiling on metal foams at saturated conditions: (a) $\mathrm{Cu}$ foams; (b) Ni foams.

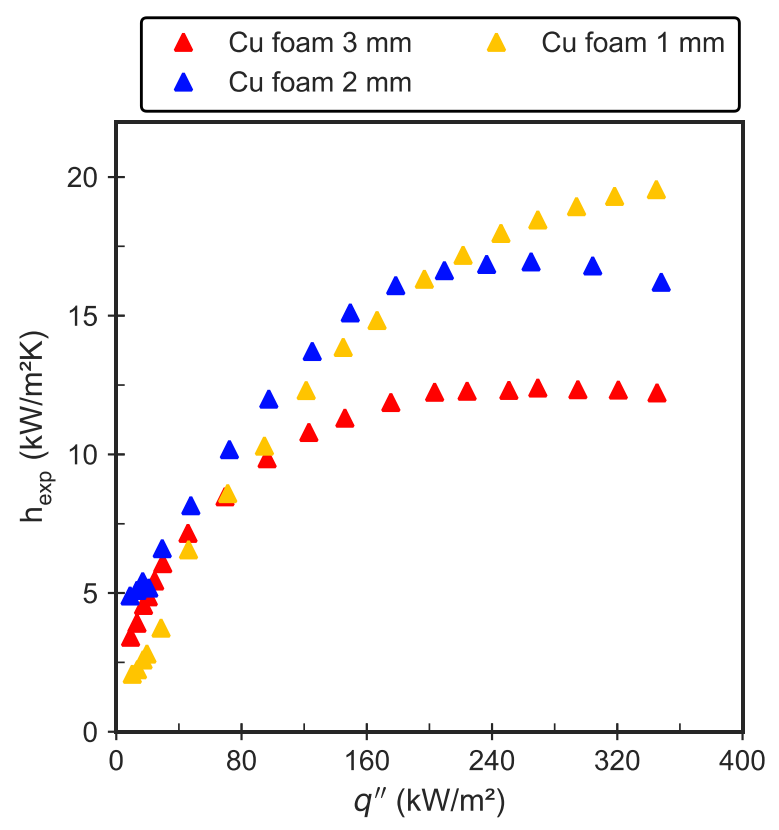

(a)

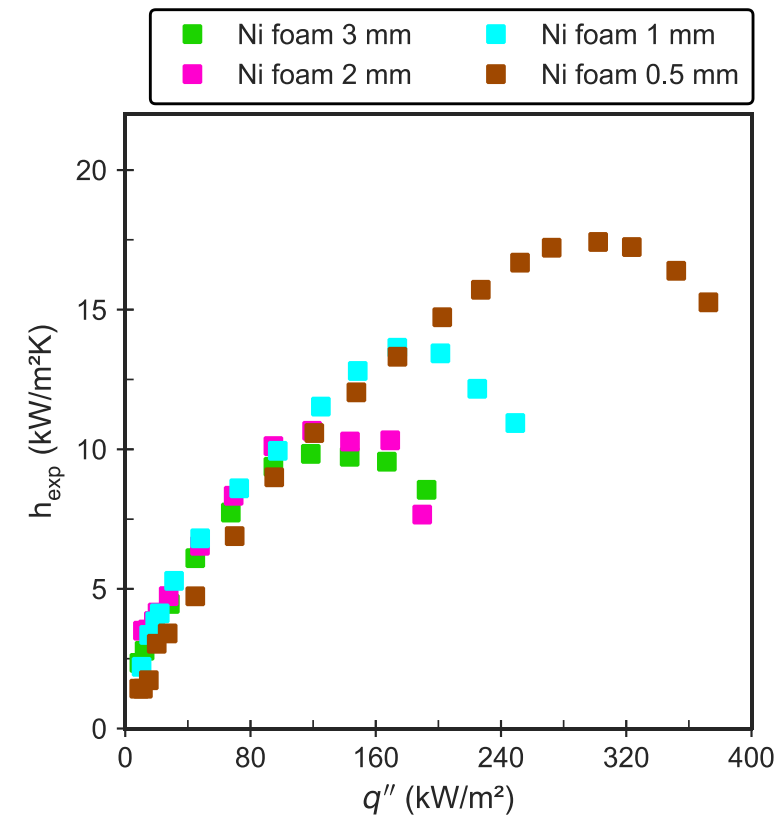

(b)

Fig. 4 HTC curves: (a) $\mathrm{Cu}$ foams; (b) Ni foams.

One may observe in Figs. 3 and 4 that the thickness level variation plays an important role in the boiling curves. Higher thickness has a greater wetted area, which can improve the heat transfer at the first heat fluxes while some nucleation sites are activated and other regions stayed on natural convection. As the heat fluxes increased, more vapor bubbles emerge from the foam structure and the boiling regimes change to fully developed nucleate boiling. In this range of heat fluxes, there is a competition of the convection area (wetted 
area) and vapor bubble resistance to outlet the foam structure. Therefore, for each heat fluxes range, there is an optimum thickness.

Another parameter on the foam heat transfer phenomenon is the pore diameter, which is correlated to the specific area (area density) as reported by Calmidi and Mahajan [23]; a lower pore diameter can result in a better heat transfer performance at low heat fluxes; however, with high thickness, it could increase the vapor bubble resistance decreasing the HTC.

Finally, the foam material properties, specifically the thermal conductivity, also play an important role in thermal behavior; the highest the thermal conductivity of the foam material the highest the effective foam thermal conductivity $[23,24]$ and, consequently, the highest the foaming efficiency (fin efficiency).

\subsection{Prediction of the Experimental Database by Using Known Correlations}

As cited in the Introduction Section, Nishikawa and Ito [17] correlated their data to predict the Nusselt number as follow:

$$
\mathrm{Nu}=\frac{h \cdot \delta}{k_{M}}=1 \times 10^{-3}\left(\frac{\sigma^{2} h_{l v}}{q^{\prime \prime 2} \delta^{2}}\right)^{0.0284}\left(\frac{\delta}{d_{s p}}\right)^{0.560}\left(\frac{q^{\prime \prime} d_{s p}}{\varepsilon h_{l v} \mu_{v}}\right)^{0.593}\left(\frac{k_{M}}{k_{l}}\right)^{-0.708}\left(\frac{\rho_{l}}{\rho_{v}}\right)^{1.67}
$$

where $\sigma, h_{l v}, k_{l}, \rho_{l}, \rho_{v}$, and $\mu_{v}$ represent the fluid thermophysical properties: surface tension [N/m], latent heat of vaporization $[\mathrm{J} / \mathrm{kg}]$, thermal conductivity $[\mathrm{W} / \mathrm{m} . \mathrm{K}]$, liquid and vapor density $\left[\mathrm{kg} / \mathrm{m}^{3}\right]$, and dynamic viscosity $[\mathrm{kg} / \mathrm{m} . \mathrm{s}]$, respectively. In addition, $d_{s p}$ represents the sintered particle diameter (solid phase of the porous medium) and $k_{M}$ is the thermal conductivity of the porous medium given by the parallel model:

$$
k_{M}=\varepsilon k_{l}+(1-\varepsilon) k_{S}
$$

In order to evaluate the capability of the previous correlation to predict HTC results for pool boiling, the experimental database was compared with the values of calculated HTC. Thus, to apply our database in Nishikawa and Ito [17] correlation, we changed $d_{s p}$ to the foam fiber diameter, $d_{f}$, because they are both the solid phase of the porous medium. In addition, the data after the highest HTC of each curve, Fig. 4, was removed because the predictive model does not consider the dryout phenomenon. Fig. 5 shows the HTC calculated by the previous correlation versus the experimental database. In addition, Table 3 presents the statistical analysis between experimental and predicted data, including the parcel of data predicted within an error band of $\pm 30 \%, \gamma_{30}$, and the mean average percentage error, MAPE, defined as follows:

$$
\text { MAPE }=\frac{\sum_{i=1}^{N}\left|\frac{h_{c a l}-h_{\text {exp }}}{h_{\text {exp }}}\right|}{N}
$$

Table 3 Comparison between HTC experimental database used in the present study and HTC predictive method from the Nishikawa and Ito [17].

\begin{tabular}{l|c|c}
\hline \multicolumn{1}{c|}{ Curve } & MAPE & $\gamma_{30}$ \\
\hline $\mathrm{Cu}$ foam $3 \mathrm{~mm}$ & $18 \%$ & $76 \%$ \\
$\mathrm{Cu}$ foam $2 \mathrm{~mm}$ & $19 \%$ & $85 \%$ \\
$\mathrm{Cu}$ foam $1 \mathrm{~mm}$ & $110 \%$ & $0 \%$ \\
$\mathrm{Ni}$ foam $3 \mathrm{~mm}$ & $50 \%$ & $6 \%$ \\
Ni foam $2 \mathrm{~mm}$ & $44 \%$ & $11 \%$ \\
Ni foam $1 \mathrm{~mm}$ & $24 \%$ & $82 \%$ \\
Ni foam $0.5 \mathrm{~mm}$ & $32 \%$ & $65 \%$ \\
\hline \multicolumn{1}{c|}{ Average } & $42 \%$ & $46 \%$ \\
\hline
\end{tabular}




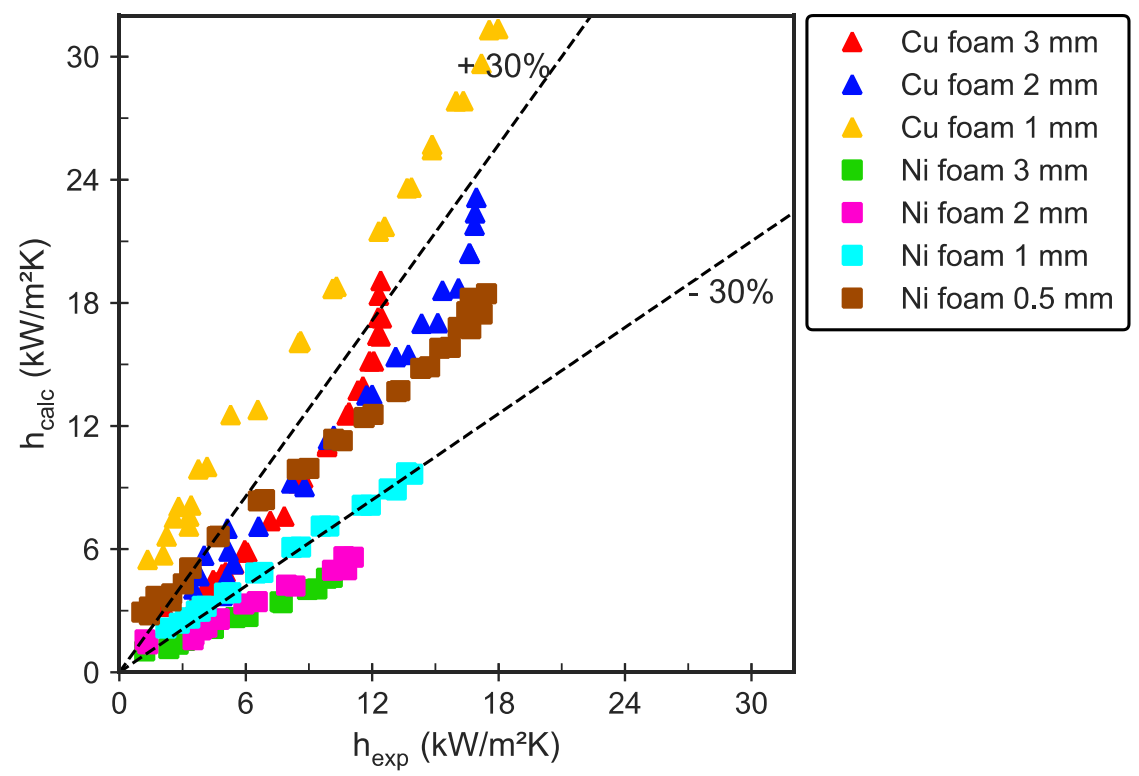

Fig. 5 Comparison between HTC experimental database used in the present study and HTC predictive methods from Nishikawa and Ito [17].

It is expected that the experimental database does not fit well with the Nishikawa and Ito correlation [17] mainly due to the surface characteristics. The sintered particle layer tested by Nishikawa and Ito [17] had a porosity range from 0.38 to 0.71 while our metal foams samples are from 0.9 to 0.98 . Moreover, the particles layer had higher particles diameter than the metal foam fiber diameter.

\subsection{New Pool Boiling HTC Predictive Model for Metal Foams}

The newly developed correlation is obtained based on the Buckingham $\pi$ theorem [25] to formulate the independent variables chosen to represent the dependent parameters. The application of this theorem first requires a decision on which of the parameters play roles on the nucleate boiling. First, the boiling phenomenon is dependent on the heat flux, $q^{\prime \prime}$. Next, as previously mentioned, the boiling HTC on metal foams is a function of surface characteristics; thus, the proposed correlation takes into account the effect of foam thickness $(\delta)$, pore diameter $\left(d_{p}\right)$ and porous media thermal conductivity or effective thermal conductivity $\left(k_{e f f}\right)$. Moreover, the fluid thermophysical properties such as the saturation temperature, $T_{\text {sat }}$; the characteristic length (capillary length), $L_{c}$; the latent heat of vaporization, $h_{l v}$; specific heat of the liquid, $c_{p_{l}}$; and dynamic viscosity of the liquid, $\mu_{l}$ also, are important parameters for the HTC predictive model. Finally, the following functional relation can be written:

$$
h=f\left(q^{\prime \prime}, L_{c}, k_{e f f}, c_{p_{l}}, T_{s a t}, \mu_{l}, h_{l v}, \delta, d_{p}\right)
$$

The $n=10$ variables are listed in the dimension MLT $\Theta$ [26] that implies in $j=4$ repeating variables $\left(q^{\prime \prime}, L_{c}, k_{m}, c_{p_{l}}\right)$ resulting in $k=n-j=6$ dimensionless variables.

The first dimensionless number obtained is the Nusselt number,

$$
\Pi_{1}=\mathrm{Nu}=\frac{h \cdot L_{c}}{k_{e f f}}
$$

which is similar to the Nusselt obtained by Teodori et al. [11] and Kiyomura et al. [27]; however, it incorporates the effective thermal conductivity from the porous media. 
The second dimensionless number,

$$
\Pi_{2}=\frac{q^{\prime \prime} \cdot L_{c}}{k_{e f f} T_{\text {sat }}}
$$

is the only one where the heat flux, $q^{\prime \prime}$, appears. That dimensionless number represents the heat flux from conduction in the porous media. A similar dimensionless number was obtained by Teodori et al. [11] and Stephan and Abdelsalam [15].

The Prandtl number appears as the third dimensionless number,

$$
\Pi_{3}=\operatorname{Pr}=\frac{c_{p_{l}} \mu_{l}}{k_{e f f}}
$$

the Prandtl number was used by Rohsenow [13] to develop his correlation. According to him, the Prandtl number is important because the heat transfer occurs directly from the heating surface to the adjacent liquid, adapting a single-phase forced convection heat transfer model to nucleate pool boiling. As reported by Gerardi et al. [10], Teodori et al. [11] and Thiagarajan et al. [28], the quenching effect, i.e., the heat transfer due to the re-formation of the thermal boundary layer, plays an important role on the nucleate boiling heat transfer.

A modified Jakob number, which accounts the sensible heat and the latent heat of vaporization, is the fourth dimensionless number, as follow,

$$
\Pi_{4}=\mathrm{Ja}^{*}=\frac{c_{p_{l}} T_{\text {sat }}}{h_{l v}}
$$

Up to now, the foam properties only was added in the effective thermal conductivity. The following numbers take into account the dimension characteristic from the metal foam. First,

$$
\Pi_{5}=\frac{\delta}{L_{c}}
$$

which is important due to the effect of thickness in the HTC, as shown in Fig. 4.

Next,

$$
\Pi_{6}=\frac{d_{p}}{L_{c}}
$$

is a dimensionless number similar to the dimensionless number proposed by Zhang et al. [29], which represents both capillary wicking and flow resistance.

Once all the $\Pi$ groups were identified, the new correlation for the pool boiling HTC on metal foams can be written as,

$$
\frac{h \cdot L_{c}}{k_{e f f}}=\mathrm{C}\left[\left(\frac{q^{\prime \prime} \cdot L_{c}}{k_{e f f} T_{\text {sat }}}\right)^{\mathrm{a}_{1}}\left(\frac{c_{p_{l}} \mu_{l}}{k_{e f f}}\right)^{\mathrm{a}_{2}}\left(\frac{c_{p_{l}} T_{s a t}}{h_{l v}}\right)^{\mathrm{a}_{3}}\left(\frac{\delta}{L_{c}}\right)^{\mathrm{a}_{4}}\left(\frac{d_{p}}{L_{c}}\right)^{\mathrm{a}_{5}}\right]
$$

where $C$ and the exponent $a_{i}$ are constant, except $a_{4}$ that was defined by the authors as a function of the heat flux, 


$$
a_{4}=f\left(q^{\prime \prime}\right)=\frac{a}{b+\exp \left(c \cdot q^{\prime \prime}-d\right)}-e
$$

that is an inverse 'S-shaped' curve, which takes into account the effect of the thickness in the boiling curve of metal foams. At low heat fluxes, as higher thickness results in higher HTC and vice-versa due to the balance of heat transfer area and vapor bubble resistance.

Based on the regression analysis of the experimental database by using the least-squares method implemented on SciPy, a Python-based library, the following correlation is proposed:

$$
\frac{h \cdot L_{c}}{k_{\text {eff }}}=23,3\left(\frac{q^{\prime \prime} \cdot L_{c}}{k_{\text {eff }} T_{\text {sat }}}\right)^{0,6086}\left(\frac{c_{p_{l}} \mu_{l}}{k_{\text {eff }}}\right)^{0,3568}\left(\frac{h_{l v}}{c_{p_{l}} T_{\text {sat }}}\right)^{0,0477}\left(\frac{\delta}{L_{c}}\right)^{f\left(q^{\prime \prime}\right)}\left(\frac{L_{c}}{d_{p}}\right)^{0,0415}
$$

where,

$$
f\left(q^{\prime \prime}\right)=\frac{7.232}{19.06+\exp \left(0.0205 \times 10^{-3} q^{\prime \prime}-0.0405\right)}-0.19
$$

and $k_{e f f}$ is given by the model from Boomsma and Poulikakos (2001),

$$
k_{e f f}=\frac{\sqrt{2}}{2 \cdot\left(R_{A}+R_{B}+R_{C}+R_{D}\right)}
$$

where the parameter $R_{A}, R_{B}, R_{C}$, and $R_{D}$ is given by Boomsma and Poulikakos [24]. Figure 6 shows the linear regression results. The dimensionless numbers showed a greater contribution of the transient heat conduction and single-phase convection than the latent heat. In addition, as the pore diameter decreases the HTC increases.

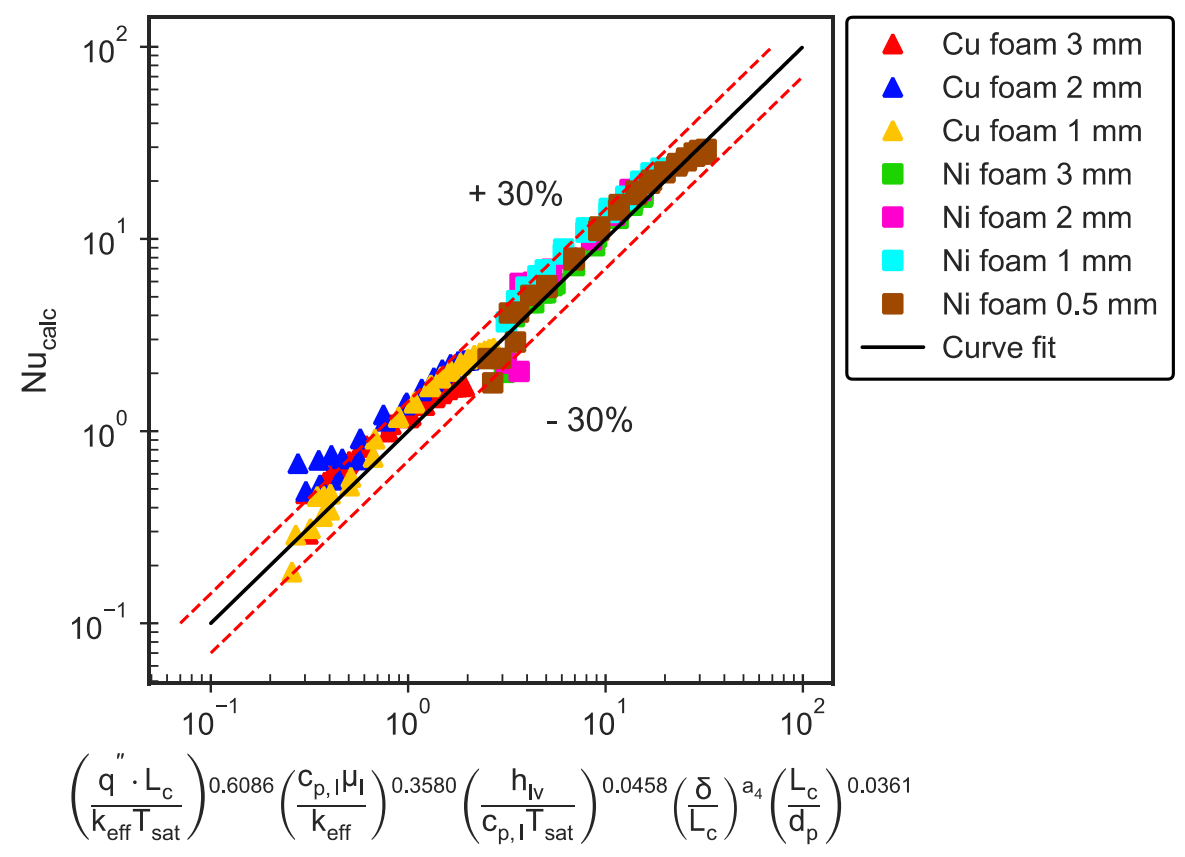

Fig. 6. Linear regression results.

\subsection{Evaluation of the Proposed Correlation}


In order to evaluate the performance of the proposed correlation, the predicted values and the experimental HTCs are plotted in Fig. 7. The proposed correlation predicts mostly of the experimental database, predicting $93 \%$ of the experimental data within an error band of $\pm 30 \%$ and with a MAPE of $13 \%$ (Table 4 ).

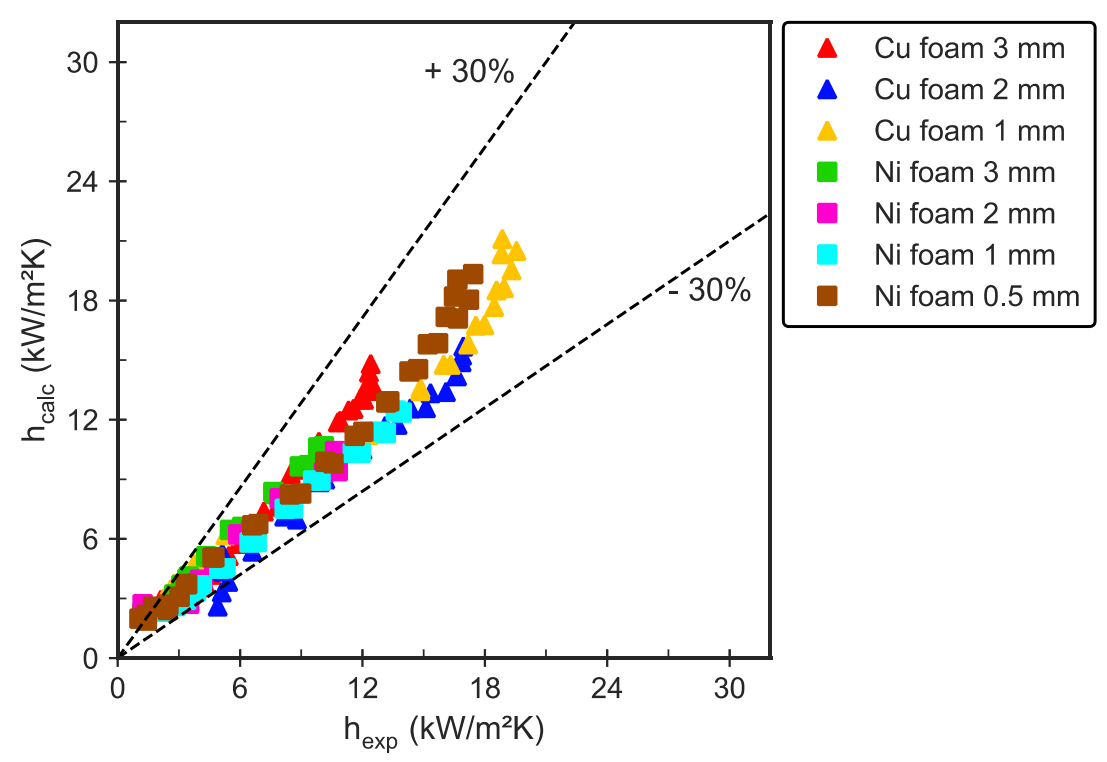

Fig. 7 Comparison between the predicted values and the experimental HTC.

Table 4 Comparison between HTC experimental database used in the present study and HTC predictive method.

\begin{tabular}{l|c|c}
\hline \multicolumn{1}{c|}{ Curve } & MAPE & $\gamma_{30}$ \\
\hline $\mathrm{Cu}$ foam $3 \mathrm{~mm}$ & $10 \%$ & $97 \%$ \\
$\mathrm{Cu}$ foam $2 \mathrm{~mm}$ & $15 \%$ & $92 \%$ \\
$\mathrm{Cu}$ foam $1 \mathrm{~mm}$ & $13 \%$ & $88 \%$ \\
$\mathrm{Ni}$ foam $3 \mathrm{~mm}$ & $16 \%$ & $94 \%$ \\
$\mathrm{Ni}$ foam $2 \mathrm{~mm}$ & $16 \%$ & $89 \%$ \\
$\mathrm{Ni}$ foam $1 \mathrm{~mm}$ & $10 \%$ & $100 \%$ \\
$\mathrm{Ni}$ foam $0.5 \mathrm{~mm}$ & $12 \%$ & $87 \%$ \\
\hline \multicolumn{1}{c|}{ Average } & $13 \%$ & $93 \%$ \\
\hline
\end{tabular}

Moreover, the performance of the proposed correlation was evaluated by comparing it with 589 experimental data points obtained by other authors, namely by Atherya et al. [30], Moghaddam et al. [31] and Xu et al. [32]. Atherya et al. [30] used aluminum foams on boiling of FC-72 while Moghaddam et al. [31] used copper foams on boiling FC-72. Xu et al. [32] also used copper foams, however, they used acetone as the working fluid; even though the working fluids were different from our experimental database, they were considered due to the wetting fluid behavior. Figure 8 shows the prediction of the independent experimental data from the literature and Table 5 shows the error analysis. 


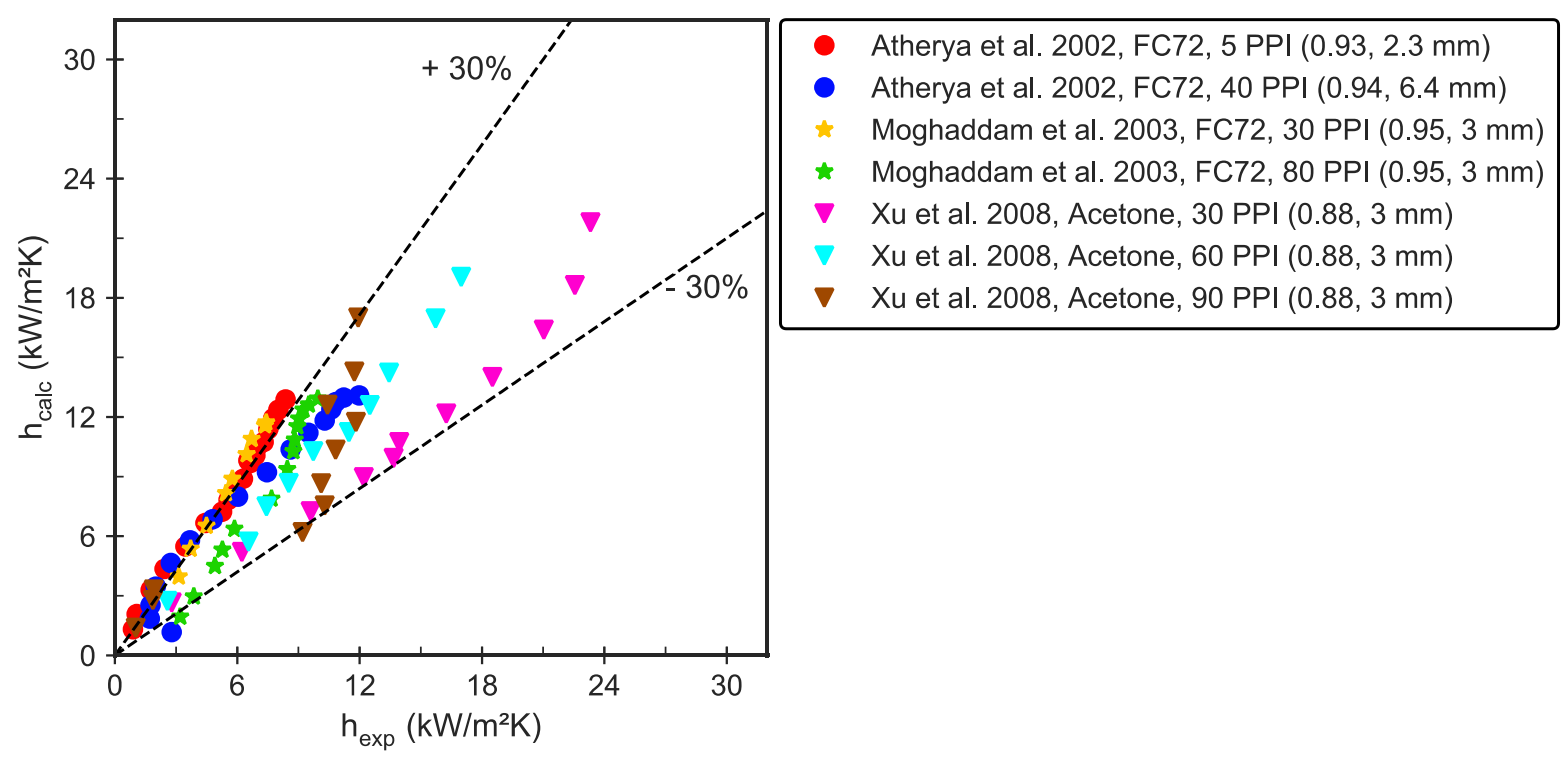

Fig. 8 Comparison between the predicted values and the HTC experimental data from the literature for wetting fluids on metal foams.

Table 5 Comparison between HTC experimental data from the literature [30 - 32] and HTC predictive method.

\begin{tabular}{c|c|c}
\hline Author/Curve & MAPE & $\gamma_{30}$ \\
\hline Atherya et al. 2002, FC72, 5 PPI $(0.93,2.3 \mathrm{~mm})$ & $54 \%$ & $0 \%$ \\
Atherya et al. 2002, FC72, 40 PPI $(0.94,6.4 \mathrm{~mm})$ & $33 \%$ & $56 \%$ \\
Moghaddam et al. 2003, FC72, 30 PPI $(0.95,3 \mathrm{~mm})$ & $51 \%$ & $11 \%$ \\
Moghaddam et al. 2003, FC72, 80 PPI $(0.95,3 \mathrm{~mm})$ & $21 \%$ & $71 \%$ \\
Xu et al. 2008, Acetone, 30 PPI $(0.88,3 \mathrm{~mm})$ & $20 \%$ & $100 \%$ \\
Xu et al. 2008, Acetone, 60 PPI $(0.88,3 \mathrm{~mm})$ & $6 \%$ & $100 \%$ \\
Xu et al. 2008, Acetone, 90 PPI $(0.88,3 \mathrm{~mm})$ & $29 \%$ & $55 \%$ \\
Xu et al. 2008, Acetone, 30 PPI $(0.95,3 \mathrm{~mm})$ & $9 \%$ & $100 \%$ \\
Xu et al. 2008, Acetone, 60 PPI $(0.95,3 \mathrm{~mm})$ & $10 \%$ & $100 \%$ \\
Xu et al. 2008, Acetone, 90 PPI $(0.95,3 \mathrm{~mm})$ & $15 \%$ & $90 \%$ \\
\hline Average & $25 \%$ & $68 \%$ \\
\hline
\end{tabular}

\section{CONCLUSIONS}

A predictive model was proposed for the heat transfer coefficient (HTC) of wetting/dielectric fluids on metal foams. The correlation was based on the dimensional analysis - Buckingham $\pi$ theorem - by using the regression of experimental database. The following conclusions can be drawn from the present study:

- The developed model predicts accurately the boiling heat transfer behavior of dielectric fluids with metal foams; the mean absolute error was close to $13 \%$ and $25 \%$ for our experimental database and for data from the literature, respectively.

- The dimensionless numbers showed a greater contribution of the transient heat conduction and singlephase convection than the latent heat. In addition, as the pore diameter decreases the HTC increases. The thickness presents a variable exponent, which is a function of the heat flux, due to the balance of heat transfer area and vapor bubble resistance. 
- The developed model accurately predicts $93 \%$ of the experimental data within an error band of $\pm 30 \%$; moreover, the developed model predicts $68 \%$ (within the $\pm 30 \%$ error band) of data from the literature for different working fluids and foams parameters.

\section{ACKNOWLEDGMENT}

The authors are grateful for the financial support from the PPGEM - UNESP/FEIS, from CAPES, from the National Council of Technological and Scientific Development of Brazil (CNPq grant number 458702/20145) and from FAPESP (grant number 2013/15431-7; 2017/13813-0; 2019/02566-8). A. S. Moita also acknowledges the contribution of FCT for financing her contract through the IF 2015 recruitment program (IF/00810/2015) and associated exploratory project.

\section{NOMENCLATURE}

$\begin{array}{clc}a_{s f} & \text { Area density } & \left(\mathrm{m}^{-1}\right) \\ d_{f} & \text { Fiber diameter } & (\mathrm{m}) \\ d_{p} & \text { Pore diameter } & (\mathrm{m}) \\ d_{s p} & \text { Sintered particle diameter } & (\mathrm{m}) \\ h_{c a l} & \text { Calculated/Predicted heat transfer coefficient } & \left(\mathrm{W} / \mathrm{m}^{2} \mathrm{~K}\right) \\ h_{\text {exp }} & \text { Experimental heat transfer coefficient } & \left(\mathrm{W} / \mathrm{m}^{2} \mathrm{~K}\right) \\ k_{M}, k_{\text {eff }} & \text { Effective thermal conductivity of the porous media } & (\mathrm{W} / \mathrm{mK}) \\ \delta & \text { Thickness } & (\mathrm{m}) \\ \varepsilon & \text { Porosity } & (-)\end{array}$

\section{REFERENCES}

[1] Tuma, P., "Evaporator/Boiler Design for Thermosyphons Utilizing Segregated Hydrofluoroether Working Fluids," Proc. of Twenty-Second Annual IEEE Semiconductor Thermal Measurement And Management Symposium, IEEE, pp. 69-77 (2006).

[2] El-Genk, M. S., 2012, "Nucleate Boiling Enhancements on Porous Graphite and Microporous and Macro-Finned Copper Surfaces," Heat Transf. Eng., 33(3), pp. 175-204.

[3] Abreu, V., Harrison, M., Gess, J., and Moita, A. S., "Two-Phase Thermosiphon Cooling Using Integrated Heat Spreaders With Copper Microstructures," Proc. of 17th IEEE Intersociety Conference on Thermal and Thermomechanical Phenomena in Electronic Systems (ITherm), IEEE, pp. 645-652 (2018).

[4] Wong, K. K. Study of heat transfer enhancement surfaces generated by additive manufacturing techniques, $\mathrm{Ph} . \mathrm{D}$. Thesis, Nanyang Technological University, (2019).

[5] Liang, G., and Mudawar, I., "Review of Pool Boiling Enhancement by Surface Modification,” Int. J. Heat Mass Transf., 128 (September 2018), pp. 892-933 (2019).

[6] Hendricks, T. J., Krishnan, S., Choi, C., Chang, C., and Paul, B., "Enhancement of Pool-Boiling Heat Transfer Using Nanostructured Surfaces on Aluminum and Copper," Int. J. Heat Mass Transf., 53(15-16), pp. 3357-3365 (2010).

[7] Shojaeian, M., and Koşar, A., "Pool Boiling and Flow Boiling on Micro- and Nanostructured Surfaces," Exp. Therm. Fluid Sci., 63, pp. 45-73 (2015).

[8] Lin, L., and Kedzierski, M. A., "Review of Low-GWP Refrigerant Pool Boiling Heat Transfer on Enhanced Surfaces," Int. J. Heat Mass Transf., 131, pp. 1279-1303 (2019).

[9] Wu, Z., Cao, Z., and Sundén, B., "Saturated Pool Boiling Heat Transfer of Acetone and HFE-7200 on Modified Surfaces by Electrophoretic and Electrochemical Deposition," Appl. Energy, 249(April), pp. 286-299 (2019).

[10] Gerardi, C., Buongiorno, J., Hu, L. wen, and McKrell, T., "Study of Bubble Growth in Water Pool Boiling through Synchronized, Infrared Thermometry and High-Speed Video," Int. J. Heat Mass Transf., 53(19-20), pp. 4185-4192 (2010).

[11] Teodori, E., Moita, A. S., and Moreira, A. L. N., "Empirical and Modeling-Based Correlations for Pool Boiling on Microstructured Surfaces," Interfacial Phenom. Heat Transf., 2(3), pp. 273-292 (2014).

[12] Cao, Z., Wu, Z., and Sundén, B., "Heat Transfer Prediction and Critical Heat Flux Mechanism for Pool Boiling of NOVEC649 on Microporous Copper Surfaces," Int. J. Heat Mass Transf., 141, pp. 818-834 (2019).

[13] Rohsenow, W., M., "A method of correlating heat transfer data for surface boiling of liquids". Transactions of ASME - J. Heat Transfer, 74, pp. 969-976 (1952).

[14] Jabardo, J. M. S., "Transferência de Calor Por Ebulição e Trocadores de Calor Bifásicos". Proc. of $1^{\circ}$ Encontro Brasileiro sobre Ebulição, Condensação e Escoamento Multifásico Líquido-Gás (2008).

[15] Stephan, K., and Abdelsalam, M., "Heat-Transfer Correlations for Natural Convection Boiling," Int. J. Heat Mass Transf., 23(1), pp. 73-87(1980).

[16] Stephan, K., Heat Transfer in Condensation and Boiling, Springer Berlin Heidelberg, Berlin, Heidelberg (1992). 
[17] K. Nishikawa and T. Ito, “Augmentation performance of boiling heat transfer". In Research on Effective Use of Thermal Energy, 1, p. 39. (1982).

[18] Xu, Z. G., Qu, Z. G., Zhao, C. Y., and Tao, W. Q., "Experimental Correlation for Pool Boiling Heat Transfer on Metallic Foam Surface and Bubble Cluster Growth Behavior on Grooved Array Foam Surface,” Int. J. Heat Mass Transf., 77, pp. 1169-1182 (2014).

[19] Manetti, L. L, Soares, P. H., and Cardoso, E. M., "Pool Boiling Heat Transfer of HFE-7100 on Metal Foams", Proc. of $10^{\text {th }}$ Int. Conf. on Multiphase Flow, Rio de Janeiro, p. 157 (2019).

[20] Groover, M. P., Fundamentals of modern manufacturing: materials processes, and systems. John Wiley \& Sons, 5th ed. (2012).

[21] 3M product brochure, "3M Novec ${ }^{\mathrm{TM}}$ engineered fluid HFE-7100 for heat transfer", (2002).

[22] Rausch, M. H., Kretschmer, L., Will, S., Leipertz, A., and Fröba, A. P., "Density, Surface Tension, and Kinematic Viscosity of Hydrofluoroethers HFE-7000, HFE-7100, HFE-7200, HFE-7300, and HFE-7500,” J. Chem. Eng. Data, 60 (12), pp. 37593765 (2015).

[23] Calmidi, V. V., and Mahajan, R. L., "Forced Convection in High Porosity Metal Foams," J. Heat Transfer, 122(3), pp. 557565 (2000).

[24] Boomsma, K., Poulikakos, D., and Zwick, F., "Metal Foams as Compact High Performance Heat Exchangers," Mech. Mater., 35(12), pp. 1161-1176 (2003).

[25] Buckingham, E., "On Physically Similar Systems: Illustrations of the Use of Dimensional Equations", Phys. Rev., 4 (4), pp. 345-376 (1914).

[26] White, F. M. Fluid Mechanics, McGraw Hill (2003).

[27] Kiyomura, I. S., Mogaji, T. S., Manetti, L. L., and Cardoso, E. M., "A Predictive Model for Confined and Unconfined Nucleate Boiling Heat Transfer Coefficient," Appl. Therm. Eng., 127, pp. 1274-1284 (2017).

[28] Thiagarajan, S. J., Yang, R., King, C., and Narumanchi, S., "Bubble Dynamics and Nucleate Pool Boiling Heat Transfer on Microporous Copper Surfaces,” Int. J. Heat Mass Transf., 89, pp. 1297-1315 (2015).

[29] Zhang, Y., Zhou, J., Zhou, W., Qi, B., and Wei, J., "CHF Correlation of Boiling in FC-72 with Micro-Pin-Fins for Electronics Cooling," Appl. Therm. Eng., 138, pp. 494-500 (2018).

[30] Athreya, B. P., Mahajan, R. L., and Sett, S., "Pool Boiling of FC-72 over Metal Foams: Effect of Foam Orientation and Geometry," Proc. of 8th AIAA/ASME Jt. Thermophys. Heat Transf. Conf., (June), pp. 1-10 (2002).

[31] Moghaddam, S., Ohadi, M., and Qi, J., "Pool Boiling of Water and FC-72 on Copper and Graphite Foams," Proc. of ASME 2003 International Electronic Packaging Technical Conference and Exhibition, 2, pp. 675-680 (2003).

[32] Xu, J., Ji, X., Zhang, W., and Liu, G., "Pool Boiling Heat Transfer of Ultra-Light Copper Foam with Open Cells," Int. J. Multiph. Flow, 34(11), pp. 1008-1022 (2008). 